\title{
MANIFESTAÇÕES PATOLÓGICAS RECORRENTES EM IMÓVEIS MODERNISTAS: O CASO DO PAVILHÃO LUIZ NUNES EM RECIFE/PE
}

\author{
EDUARDA ALVES DE BARROS, KAMYLA \\ Graduanda em Arquitetura e Urbanismo \\ Faculdade de Ciências Humanas - ESUDA \\ Pernambuco;Brasil \\ eduardaabarros2@gmail.com
}

\author{
DE ARIMATÉA ROCHA,EUDES \\ Engenheiro/docente \\ Faculdade de Ciências Humanas - ESUDA \\ Pernambuco; Brasil \\ eu_des@hotmail.com
}

\author{
OLIVEIRA DOS SANTOS,JÚLIA \\ Graduanda em Arquitetura e Urbanismo \\ Faculdade de Ciências Humanas - ESUDA \\ Pernambuco;Brasil \\ julia_oliveiras@hotmail.com
}

\section{RESUMO}

Assim como os seres humanos, as edificações também possuem um ciclo de vida e podem ser atingidas por manifestações patológicas que acarretarão no comprometimento do desempenho dos elementos edificados, podendo mesmo levá-los ao colapso de suas estruturas, caso não haja medidas para identificação prévia destes danos. O presente trabalho visa analisar as condições atuais de integridade construtiva do Pavilhão Luiz Nunes, obra do arquiteto Luiz Nunes datada de 1934 e considerada um marco da Arquitetura Moderna de Pernambuco e do Brasil, assim como propõe uma análise das manifestações patológicas de aparecimento recorrente nesta edificação, explanando possíveis mecanismos que poderiam prevenir e sanar estas anomalias construtivas. O estudo será desenvolvido através da produção de plantas-baixas e fachadas por meio do software Autocad visando a elaboração de mapas de danos que têm a intenção de registrar graficamente o quantitativo de manifestações patológicas recorrentes encontradas na edificação. A análise realizada no estudo em tela apresentou fatores concernentes à falta de manutenção de edificações modernistas na cidade do Recife e sua relação com o desenvolvimento de manifestações patológicas.

Palavras-chave: mapa de danos; manifestações patológicas; arquitetura moderna.

\section{ABSTRACT}

As human beings, buildings also have a life cycle and can be affected by pathological manifestations that will compromise the performance of the built elements, and may even lead them to the collapse of their structures, if there are no measures for the identification of the damage. The present work aims to analyze the current conditions of constructive integrity of the Luiz Nunes Pavilion, a work by the architect Luiz Nunes dating from 1934 and considered a landmark of Modern Pernambuco and Brazil Architecture, as well as proposing an analysis of the pathological manifestations of recurrent appearance in this building, explaining possible mechanisms that could prevent and remedy these constructive anomalies. The study will be developed through the production of floor plans and facades through the Autocad software aiming at the elaboration of damage maps that intend to graphically record the amount of recurrent pathological manifestations found in the building. The analysis carried out in this paper showed factors concerning the lack of maintenance of modernist buildings in the city of Recife and its link with the development of pathological manifestations.

Keywords: damage map; pathological manifestations; modern architecture.

\section{INTRODUÇÃO}

Segundo Paulo Helene (1992 p. 19) o estudo das patologias das edificações é uma ciência da área da engenharia diagnóstica que avalia as causas, sintomas e mecanismos das falhas construtivas, objetivando uma análise do que compõe um diagnóstico patológico.

A identificação destas manifestações patológicas, em estágio inicial é imprescindível para a manutenção das edificações, evitando, dirimindo ou cessando processos de deterioração dos seus componentes. 
Os processos de degradação estão ligados diretamente e sinergicamente ao aparecimento de patologias, posto que um fator influencia diretamente o outro. Estes processos podem ser físicos, químicos ou biológicos, afetando a durabilidade, reduzindo e prejudicando o desempenho das estruturas e materiais (ROCHA, 2017).

A carência de manutenção periódica pode culminar no reaparecimento destas manifestações, que também podem ressurgir por não terem sido sanadas de maneira eficaz. Em Bauer (1987 p. 407) os elementos em concreto carecem de cuidados permanentes nas suas fases de concepção, execução e manutenção. Quanto maior o esmero nas fases supracitadas, menor será a probabilidade de uma deterioração precoce do material. Edificações modernistas, como a edificação objeto deste estudo, utilizam largamente o concreto armado como sistema construtivo, daí origina-se a necessidade permanente de manutenção.

Devido ao descaso e carência de consideração pela importância dos exemplares modernos no Recife, algumas edificações, apesar dos esforços de órgãos e profissionais que levam em consideração sua importância, padecem de constantes problemas construtivos devido à ausência de manutenção pelos mais diversos motivos. Neste contexto o antigo Pavilhão de Verificação de Óbitos da Universidade Federal de Pernambuco, atual Pavilhão Luiz Nunes (figura 01), surge como exemplo de obra modernista que apesar de processos de restauro, a carência de manutenção ocasiona o reaparecimento de manifestações patológicas.

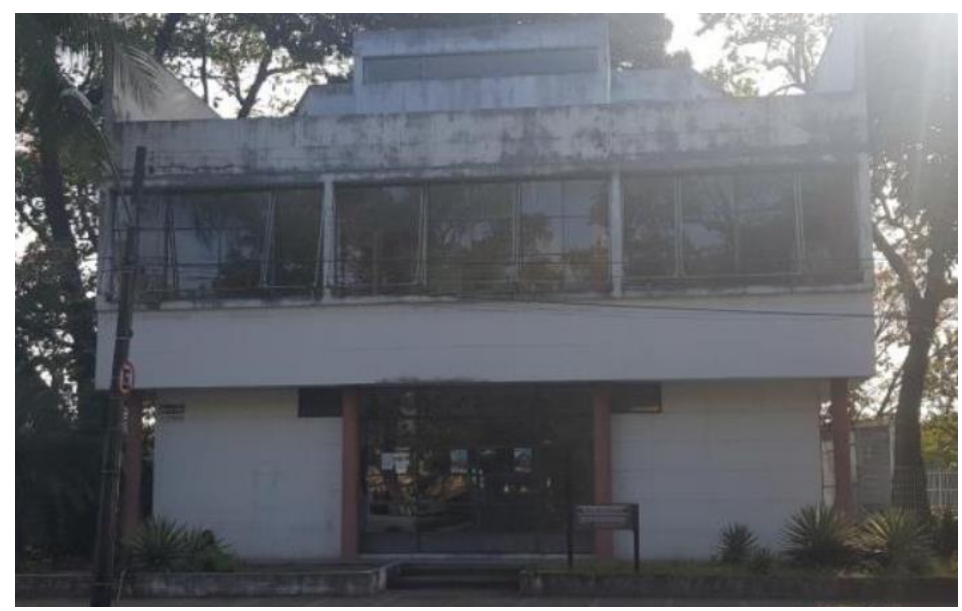

Figura 01: Fachada Oeste do Pavilhão Luiz Nunes em julho de 2019.

\section{ANAMNESE DO PAVILHÃO LUIZ NUNES}

Entre os anos 1934 e 1937, Pernambuco viu a aurora do Modernismo graças ao espírito vanguardista de Luiz Nunes e os brilhantes membros de sua equipe que compunham a Diretoria de Arquitetura e Urbanismo, da qual faziam parte Joaquim Cardozo, Gass Estelita e Fernando Saturnino de Britto (NASLAVSKY, 2012, p. 36)

Como exemplo da arquitetura vanguardista de Nunes e equipe, encontra-se o lado da antiga Faculdade de Medicina do Pernambuco, no bairro do Derby, em Recife capital do estado de Pernambuco, o edifício que outrora abrigou o Pavilhão de Verificações de Óbitos da Faculdade de Medicina de Pernambuco e que hoje possui a alcunha de Pavilhão Luiz Nunes, em homenagem ao arquiteto líder da Diretoria de Arquitetura e Urbanismo já mencionada (figura 02). A edificação implantada às margens do Rio Capibaribe, encontra-se em zona de atmosfera de rio, distando apenas 26 metros da bacia do referido rio, enquadrando a edificação em zona de agressividade ambiental 3, considerada forte pela NBR 6118 (ABNT, 2014).

A edificação atendia a Faculdade de Medicina abrigando as atividades pertinentes ao Laboratório de Anatomia Patológica. No ano de 1984, o Instituto Brasileiro de Arquitetura (IAB-PE) passa a utilizar o imóvel como sede do órgão, onde permanece até os dias atuais. 


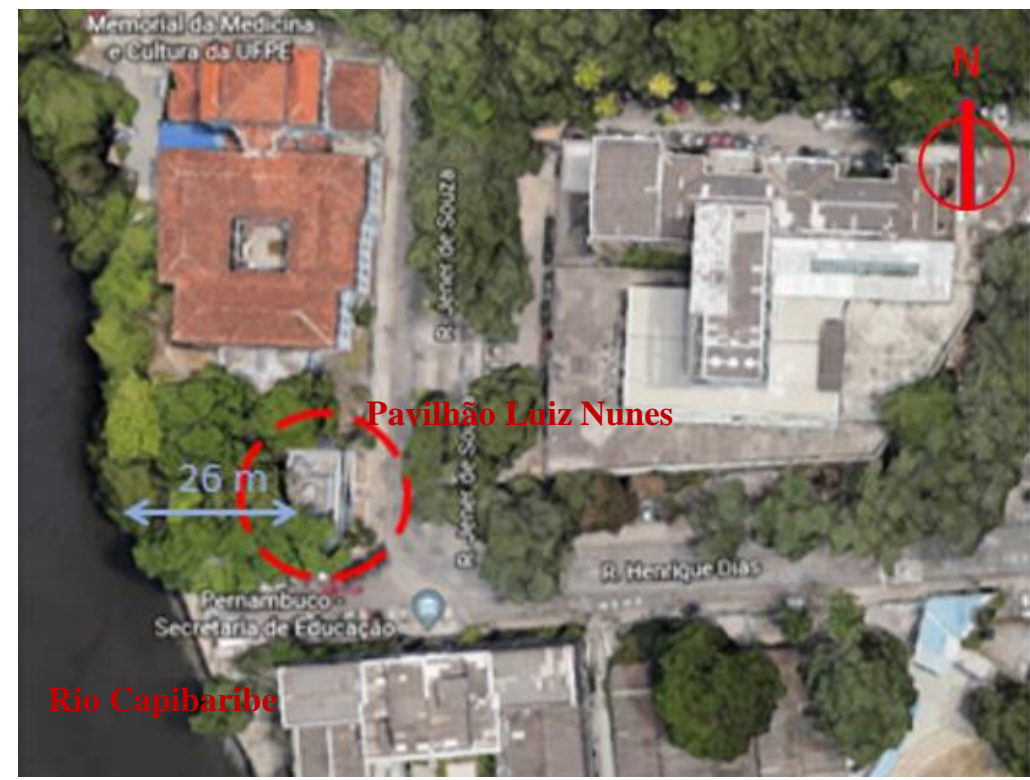

Figura 02: Localização do Pavilhão Luiz Nunes no Bairro do Derby, Recife-PE apontando a distância com o Rio Capibaribe.

Fonte: Google Earth.com, adaptado pelos autores,2019.

A importância da obra objeto desta análise (figura 03), assim como de outros exemplares da Arquitetura Moderna, foi reconhecida internacionalmente através da exposição promovida pelo Museu de Arte Moderna de Nova York - MoMA, intitulada Brasil builds archtetcture new and old 1965-1942, realizada no ano de 1943 apresentando fotografias e projetos de exemplares da arquitetura brasileira (BARATTO,2018).

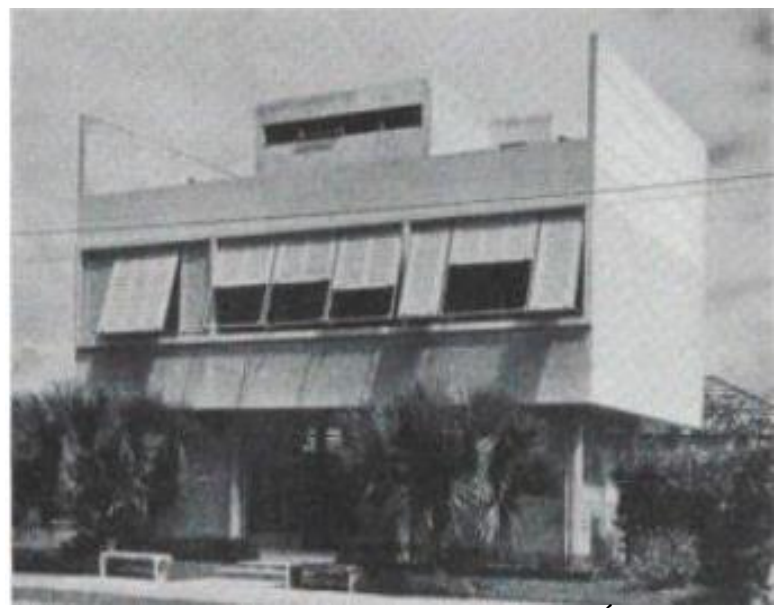

Figura 03: Pavilhão de Verificação de Óbitos da UFPE, atual Pavilhão Luiz Nunes.

Fonte: Revista Brazil Builds, 1943.

Devido a notoriedade na obra, no ano de 1984 o IAB-PE requereu a abertura do processo de tombamento da obra, para que esta pudesse obter a proteção do Estado no que tange as políticas de preservação dos bens tombados, não sendo admitido de agora em diante que a obra fosse descaracterizada por usos indevidos, adições, demolições ou alterações que corrompessem sua composição formal (FUNDARPE,1984). No ano de 1986 o prédio foi tombado na esfera estadual, seguido pelo tombamento nacional no ano de 1998 (MEDEIROS, NASLASVKY e AMORIM, 2003), (FUNDARPE,1984).

Apesar de tombado, com o passar dos anos a edificação passou por um processo de deterioração que fez com que a unidade pernambucana do Instituto de Arquitetos do Brasil, iniciasse no ano de 2002 um processo de restauro para a edificação (figuras 04,05,06,07). Neste processo foi proposto e executado: recuperação de pilares, vigas e lajes de 
concreto armado cujas armaduras estavam oxidadas e nos quais havia desagregação de argamassa; substituição das superfícies de rebocos exteriores e interiores em processo de desagregação; revisão e recuperação da instalações hidrossanitárias e elétricas existentes, impermeabilização da laje do terraço-jardim, reparo e pintura das esquadrias metálicas em toda a edificação e uma recuperação completa das superfícies de piso da edificação, incluindo a substituição dos ladrilhos hidráulicos danificados no piso do pavimento térreo (ANDRADE, CAMARA E MEDINA, 2003).

O registro fotográfico realizado antes dos trabalhos de restauro do Pavilhão Luiz Nunes, foram realizados pelos autores do documento apresentado no ano de 2003 que relata o processo de restauro ocorrido em 2002. Após o restauro, o levantamento fotográfico foi realizado no ano de 2005 pelo escritório Andrade e Raposo Arquitetos, responsável pela obra.

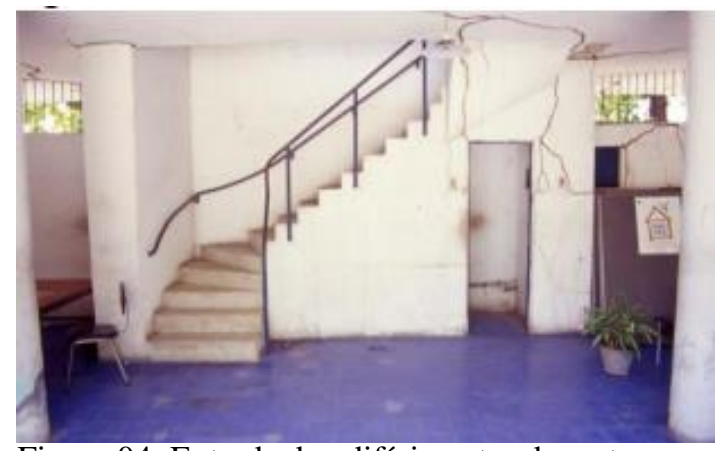

Figura 04: Entrada do edifício antes do restauro. Fonte: Andrade, Câmara e Medina,2003.

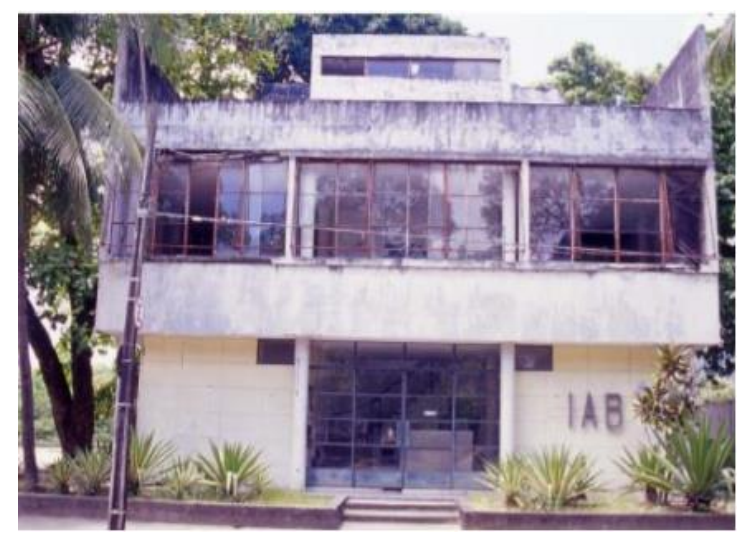

Figura 06: Fachada Oeste,antes do restauro de 2002. Fonte: Andrade, Câmara e Medina,2003.

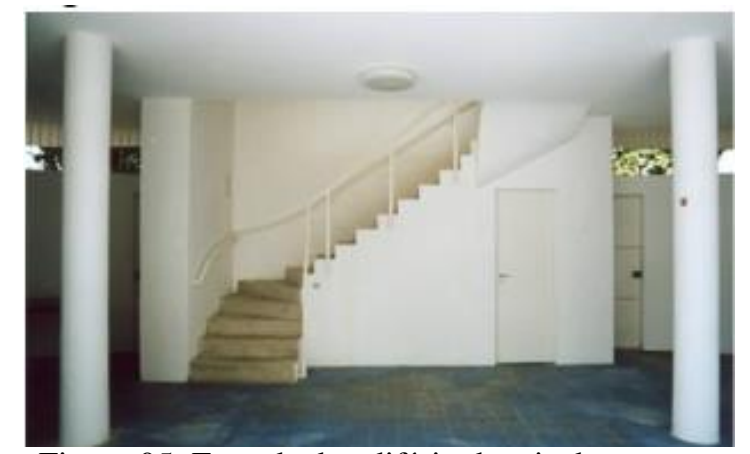

Figura 05: Entrada do edifício depois do restauro. Fonte: Andrade e Raposo Arquitetos,2005.

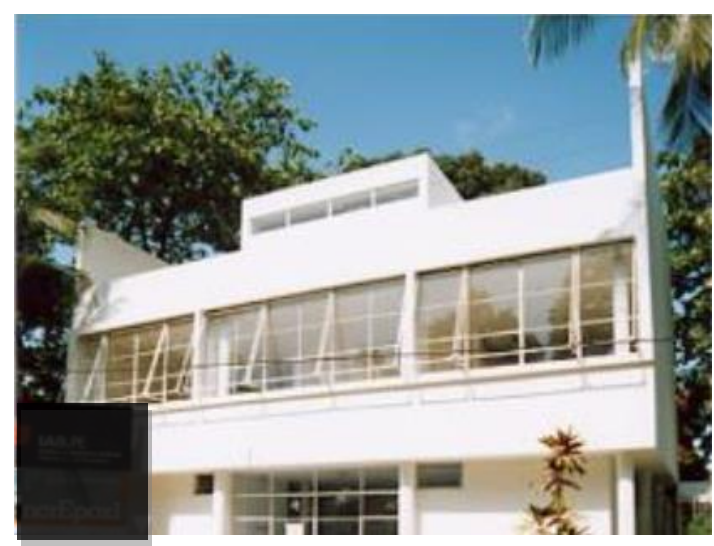

Figura 07: Fachada Oeste,após o restauro de 2002. Fonte: Andrade e Raposo Arquitetos,2005. 
Diante da análise realizada pelos autores do estudo em tela, do material fotográfico já existente e apresentado em estudos referenciados neste trabalho, foi possível constatar dados que complementam o registro que relata o processo de restauro do Pavilhão em 2002. Verificando a figura 08 e a já apresentada figura 03, é possível também detectar a presença de biodeterioração causada por ataque de xilófagos - cupins, formando desenhos irregulares semelhantes a riscos na laje e nas paredes do edifício.

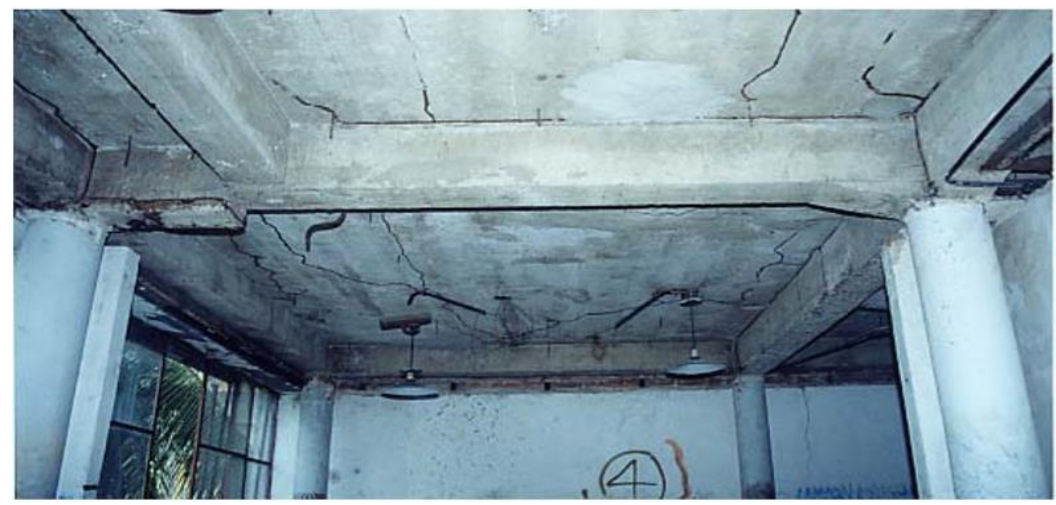

Figura 08: Forro retirado mostrando ataque de xilófagos na edificação antes da reforma.

Fonte : Andrade, Câmara e Medina,2003

Em 2015, uma nova avaliação dos danos da edificação foi realizada e o resultado aponta a reaparição de danos verificados no último processo de restauro registrado. Parte das anomalias ocorrem por influência do meio natural onde a edificação está inserida, como a oxidação causada pela proximidade, com o Rio Capibaribe. Outro exemplo é a reaparição dos depósitos escuros nas fachadas (figura 09).

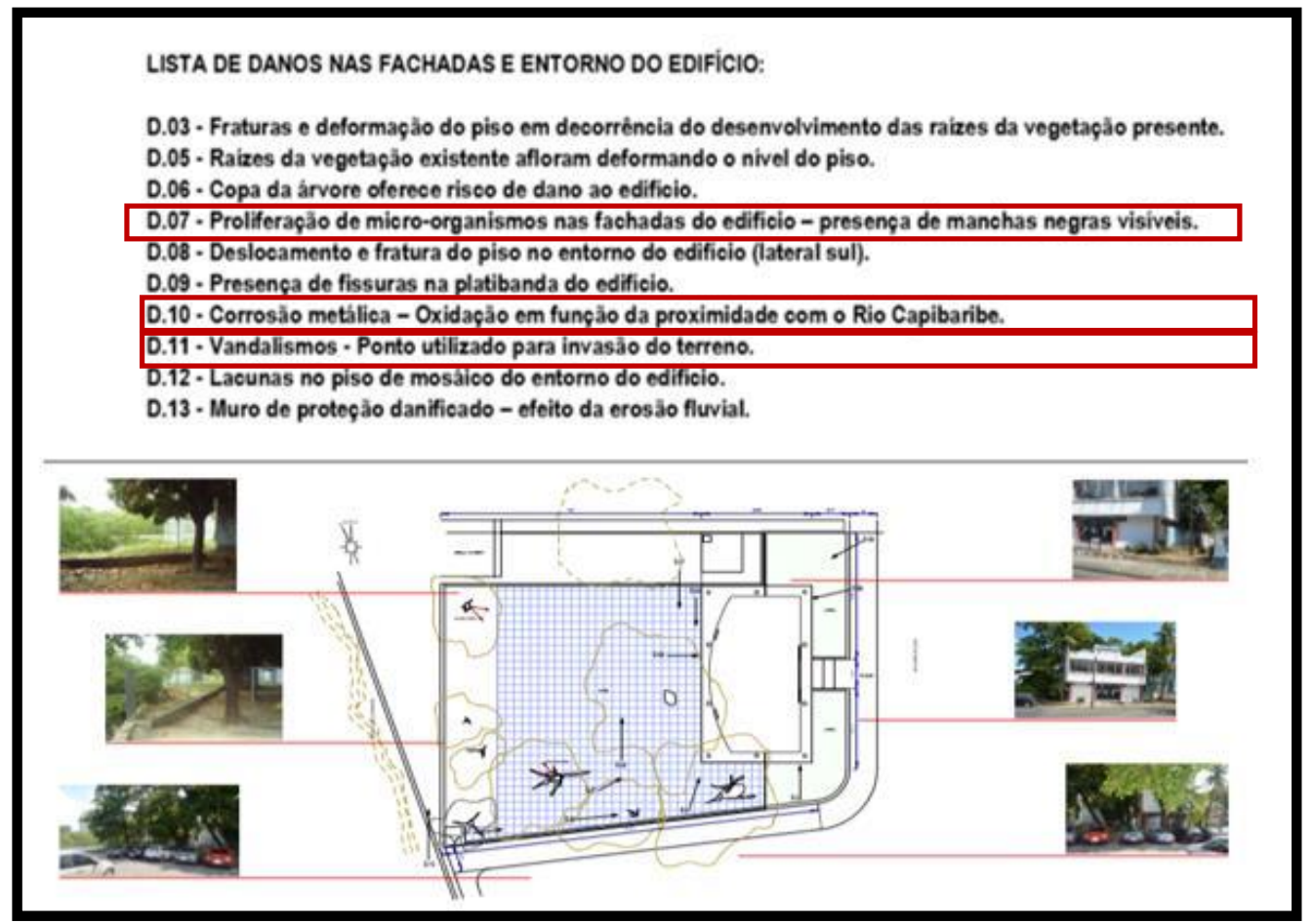

Figura 09: Mapa de danos desenvolvido para avaliação da edificação

Fonte: Andrade e Raposo Arquitetos, adaptado pelos autores,2015.

Apesar dos esforços de órgãos como o Instituto de Arquitetos do Brasil e pessoas que reconhecem o valor da obra referida, o estado de conservação do Pavilhão, se manteve aquém do estado em que este deveria se encontrar durante um longo período de tempo. Segundo a arquiteta e membro da diretoria do IAB-PE Sra. Beatriz Meunier Ferraz, a 
Universidade Federal de Pernambuco requisitou no final do segundo semestre de 2018, que as instalações do prédio fossem direcionadas doravante para abrigar programas da Universidade que visavam a maior participação dos programas da UFPE no centro do Recife. Essa ação resultou no fechamento do prédio por meses.

Com as declarações da arquiteta, chega-se à conclusão de que o trancamento do prédio foi um fator decisivo para agravar a situação e colaborar com o avanço das manifestações patológicas encontradas na edificação no momento da vistoria realizada no fim do segundo semestre de 2019 pelos autores. É válido salientar que alguns dos danos encontrados comprometem a segurança do local e a integridade física e estética do edifício tombado.

Em outubro de 2019, novamente, novos trabalhos de restauro foram iniciados para abrigar de forma satisfatória e salubre, setores da UFPE e o Instituto de Arquitetos do Brasil, entretanto até meados de agosto de 2019, o prédio apresentou manifestações patológicas recorrentes, já vistas em registros fotográficos anteriores a estes datados do ano deste trabalho acadêmico (figura10).

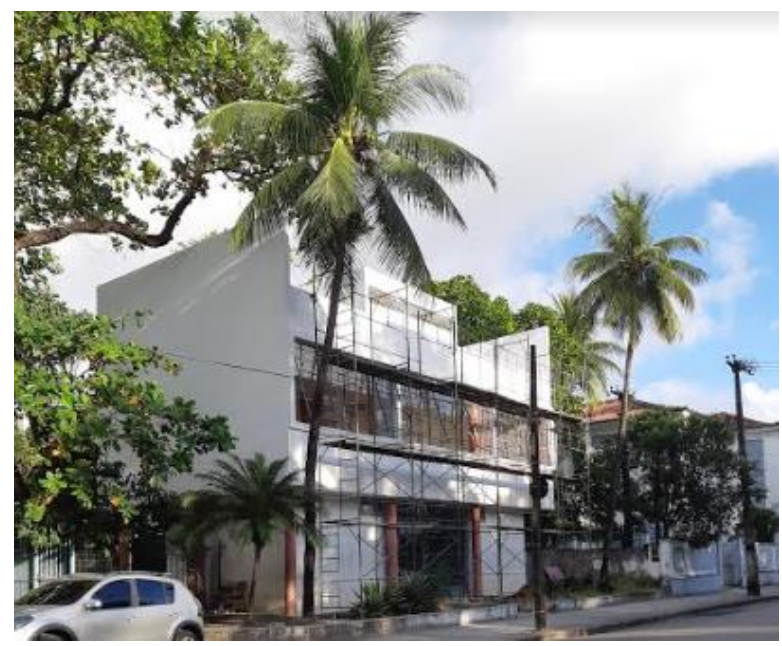

Figura 10: Processo de restauro ocorrendo em outubro de 2019.

Estas manifestações patológicas não sanadas em seu cerne ou devidamente controladas, são passíveis de retornar possivelmente de forma potencializada. A carência de manutenção periódica em qualquer edificação, seja por falta de consideração ou por falta de recursos financeiros tende a levar esta edificação a um estado de degradação paulatina. A edificação proposta neste estudo se enquadra na segunda opção apresentando-se como um exemplar de arquitetura moderna cujo valor, apesar de reconhecido por meio de instrumentos de proteção, não foi devidamente reconhecido no tocante aos subsídios para sua manutenção.

\section{INSPEÇÃO E DIAGNÓSTICO - MANIFESTAÇÕES PATOLÓGICAS RECORRENTES NO PAVILHÃO LUIZ NUNES}

A reaparição das manifestações patológicas é um produto do meio no qual a edificação está inserida associada a falta de elementos que combatam o efeito do ambiente natural na edificação. Quando existe uma ação antrópica no meio natural deve-se considerar a influência deste meio no produto desta ação e tomar as medidas preventivas para que estas degradem o mínimo o possível o elemento construído. É sabido, que na década de trinta não havia o conhecimento técnico e científico que existe hoje, para que determinadas atitudes preventivas fossem tomadas. Também deve-se considerar o empirismo e o pioneirismo empregados no uso de novas técnicas e materiais construtivos contemporâneos aos seus projetistas e executores.

Ademais, o uso de mapas de danos é um documento onde consta a representação ilustrada fundamental para o conhecimento da situação na qual se encontra uma edificação no que concerne os danos e manifestações patológicas existentes nos seus componentes (TINOCO,2009). No afim de padronizar as informações apresentadas nos mapas de danos e otimizar a legibilidade do documento proposto, o Engenheiro Eudes Rocha (2017) desenvolveu um padrão de legenda para apresentação de mapas de danos, cujo uso foi cedido para este trabalho. A reaparição de xilófagos, assim como outros danos recorrentes na edificação, podem ser vistos nos mapas de danos das fachadas da edificação desenvolvidos a seguir. 
No mapa de danos (figura 11) ilustrado acima, é possível ver o acúmulo de depósitos escuros no detalhe 1 ( figura 12 ) que podem ter sido causados por microrganismos e/ou pela exposição ao $\mathrm{C}_{2}$. A oxidação das esquadrias também é visível nas janelas e porta de entrada da edificação (Detalhes 2 e 3) vistos nas Figuras 13 e 14.

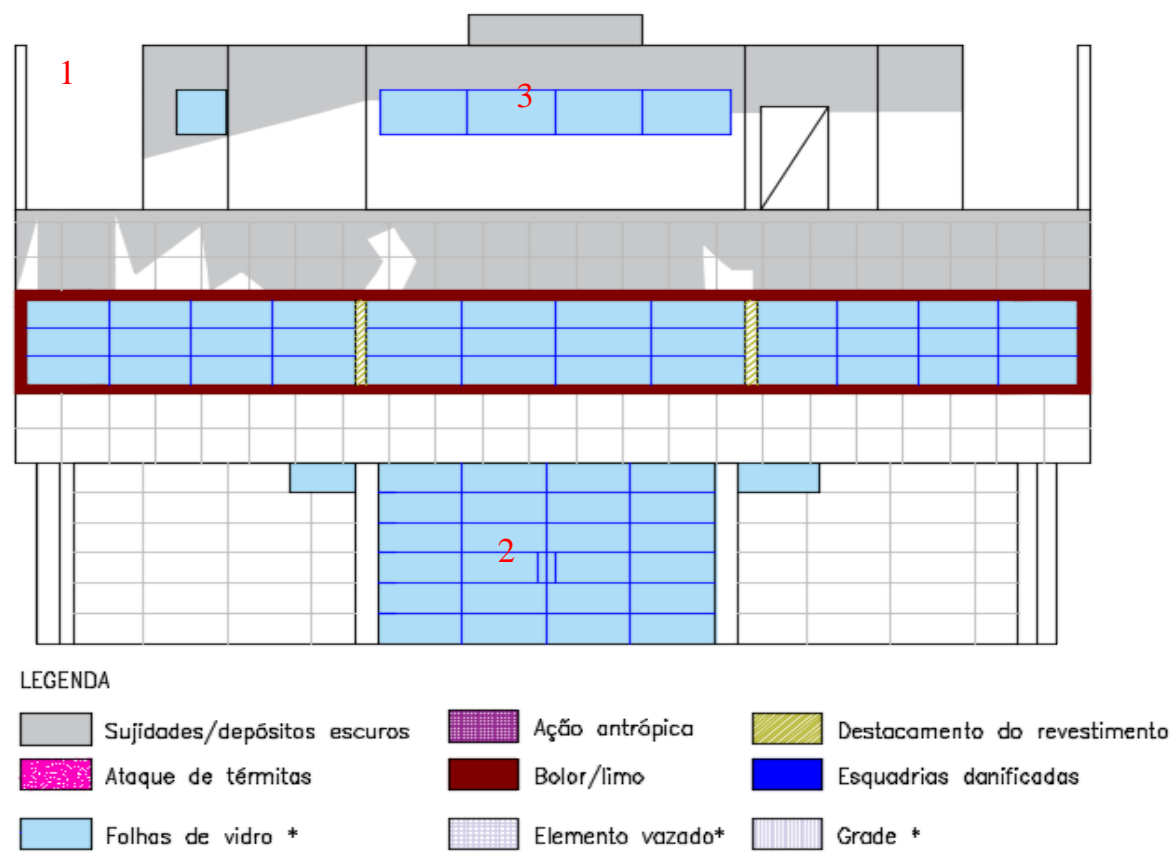

*Esta legenda não representa um dano/patologia.

Figura 11: Mapa de danos - Fachada Oeste.

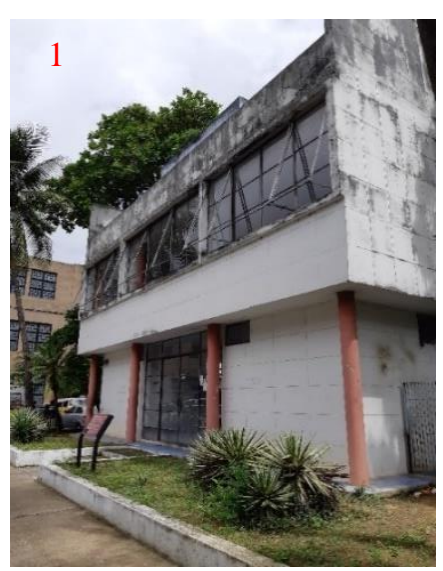

Figura 12: Depósitos escuros nas fachadas

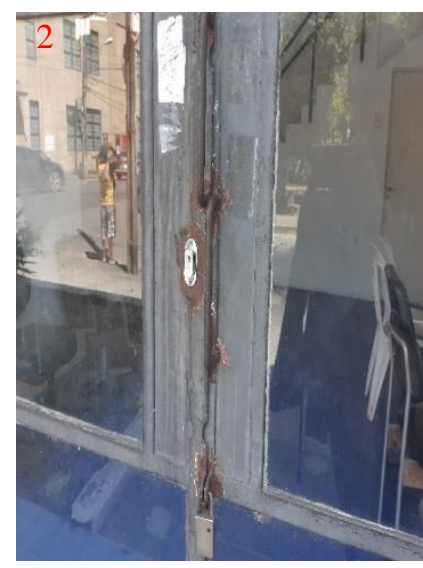

Figura 13: Esquadrias deterioradas -porta.

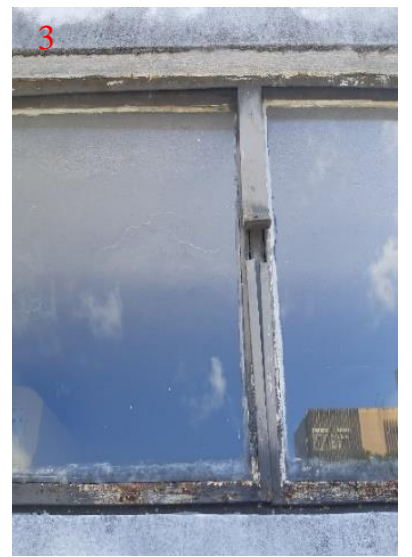

Figura 14: Esquadrias deterioradas- janela.

As fachadas Sul e Norte, são as mais preservadas apesar da reaparição de depósitos escuros oriundos das umidades e relativa do ar e da poluição atmosférica, na parte superior de sua superfície (figuras 15,16,17 e 18) 


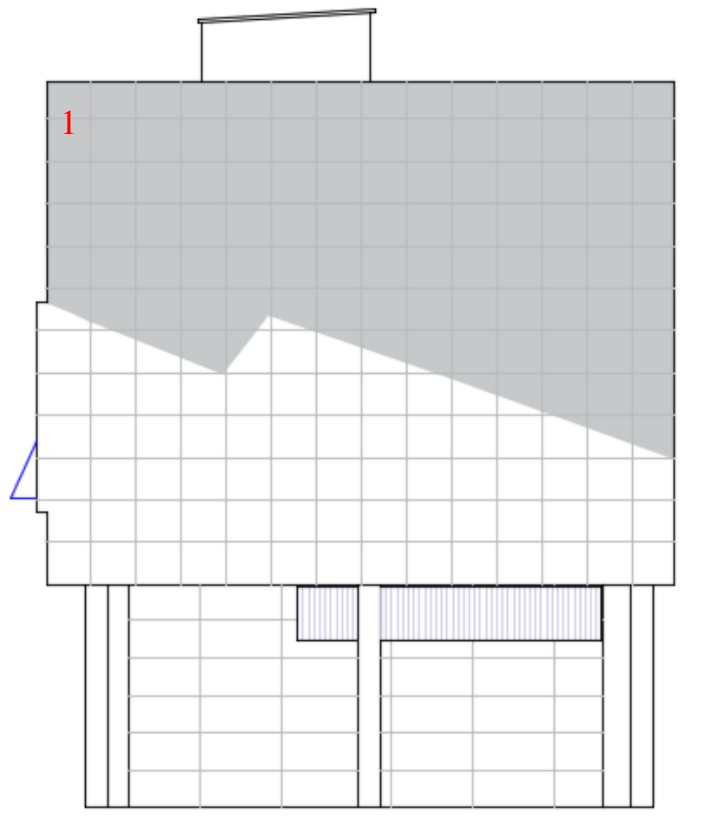

LEGENDA

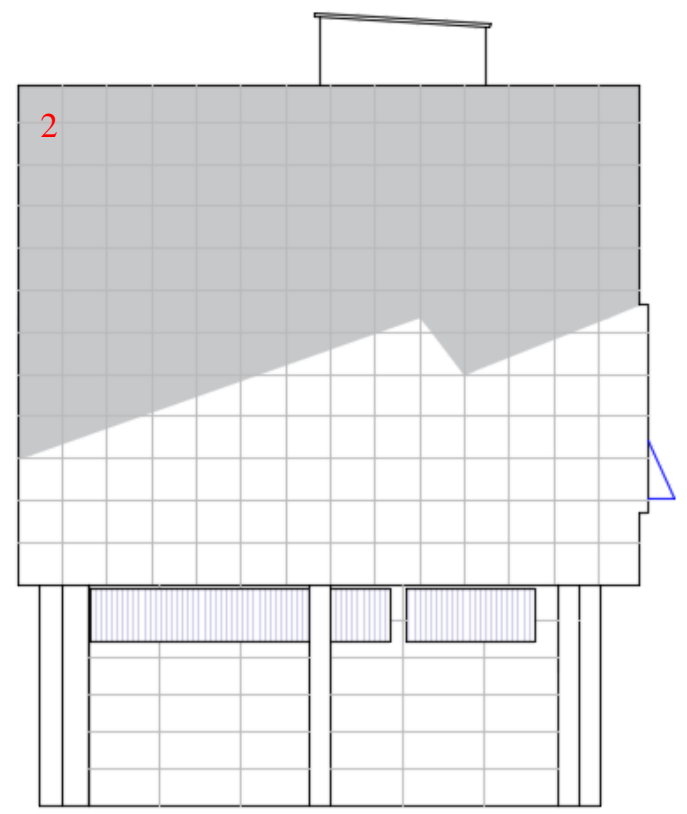

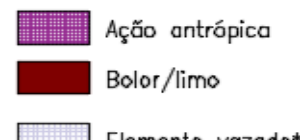

Elemento vazado*

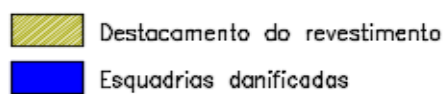

Esquadrias danificadas Grade *

*Esta legenda não representa um dano/patologia.

Figura 15: Mapa de danos fachada Sul.

Figura 16: Mapa de danos fachada Norte.

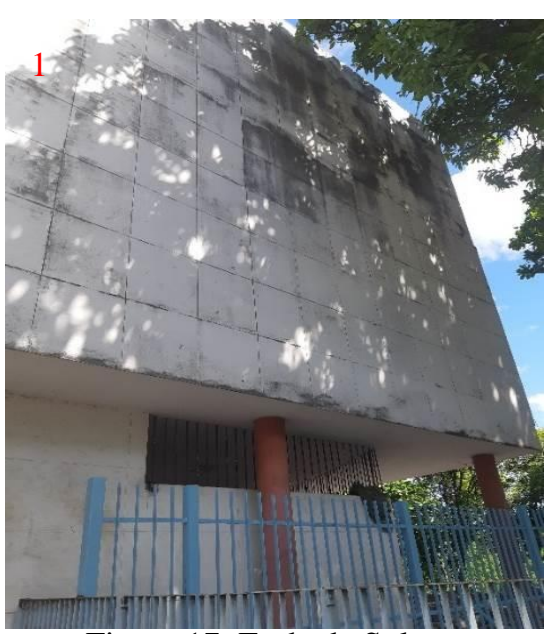

Figura 17: Fachada Sul.

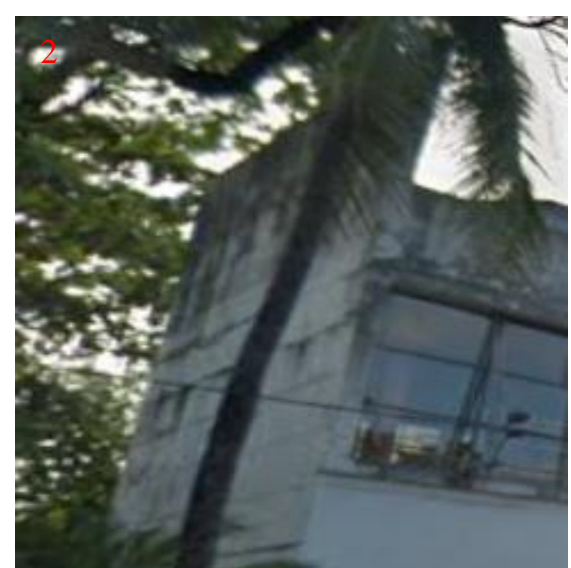

Figura 18: Fachada Norte. Fonte: google earth.com,2019.

Na fachada Leste (figuras 19 e 20), não muito diferente das demais é possível verificar a presença dos depósitos escuros que retornam de maneira contumaz à edificação, entretanto o que chama a atenção é o discreto caminho traçado pelos cupins partindo do solo até o interior da edificação. Analisando as manifestações patológicas recorrentes, fica evidente que o ataque por térmitas é a que mais se proliferou em razão da falta de manutenção da edificação. 

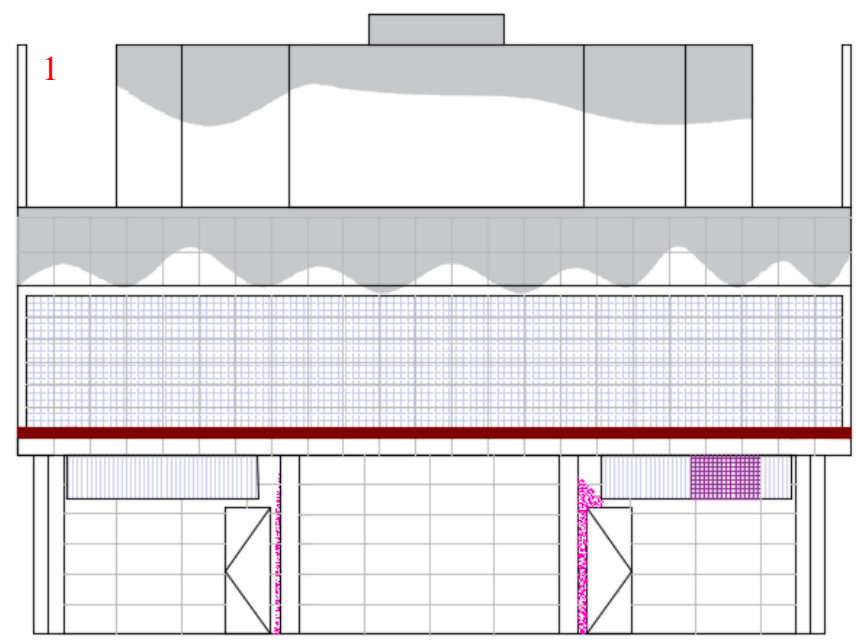

LEGENDA

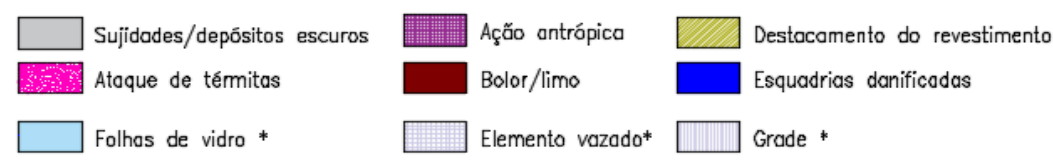

*Esta legenda nã representa um dano/patologia.

Figura 19: Mapa de danos fachada Leste

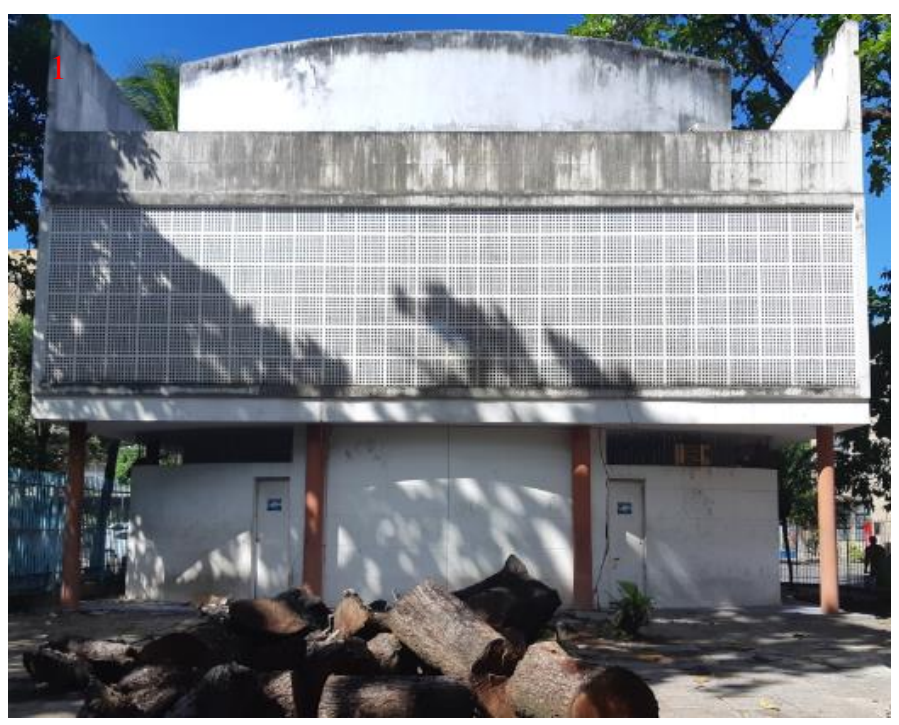

Figura 20: Fachada Leste.

Das manifestações patológicas apontadas, as mais relevantes são a reaparição de depósitos escuros em função da umidade e poluição atmosférica, e o ataque por xilófagos. Este último identificado como ataque realizado por cupins em razão dos seus resíduos de fezes granuladas e escuras (GONZAGA,2009).

No caso do ataque por térmitas foi possível constatar in loco que apesar da manifestação destes insetos se mostrar pontualmente na fachada Leste, internamente, as condições do primeiro e segundo pavimento da edificação (figuras 21 e 22) se mostravam mais comprometedoras. Os dois andares referidos estão sofrendo uma infestação de xilófagos consequências do abandono do prédio, assim como outras áreas da edificação. 


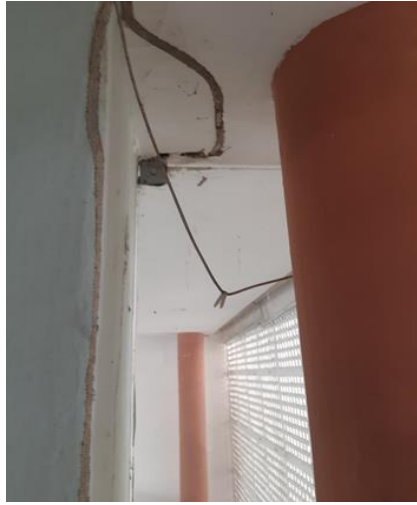

Figura 21- Ataque de térmitas no primeiro pavimento

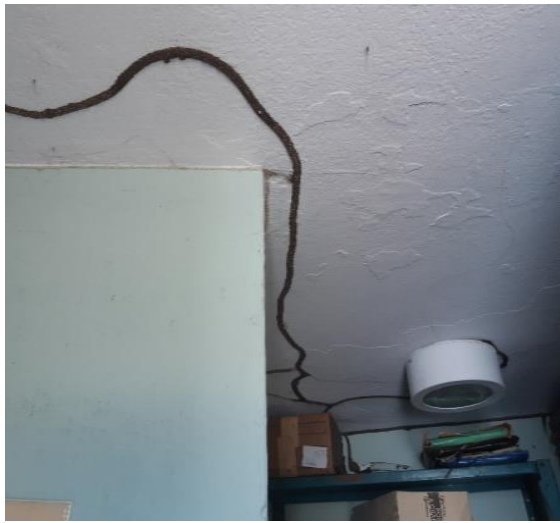

Figura 22- Ataque de térmitas no segundo pavimento

Segundo Gallo el al. (2002) os cupins subterrâneos, Rhinotermididae, é o grupo de cupins que mais causa danos mundialmente. Estes insetos xilófagos têm suas colônias inteiramente ou parcialmente no solo. 0 crescimento exponencial de térmitas pelo território nacional se deu pelas intervenções humanas no solo e o ataque biológico causado por estes animais representa um sério risco para elementos construídos. Estes insetos xilófagos são indivíduos pertencentes a uma colônia, que em geral, possui milhões deles. Atacando silenciosamente e originando uma série de problemas estéticos e estruturais para uma edificação, pois apesar da sua alimentação ser majoritariamente a base de celulose, eles danificam outros materiais, a exemplo do próprio concreto (ecofocus.com,2015). Ainda, segundo Gonzaga (2006), deve-se considerar que no nosso clima tropical ou subtropical, o ataque biológico se dá de forma mais acentuada do que no clima frio, fato que agrava as condições já complicadas da edificação, em razão da sua implantação.

No tocante a reaparição dos depósitos escuros vistos nas imagens do processo de restauro de 2002 e também pontuada no mapa de danos desenvolvido em 2015 conclui-se segundo Carvalho et al. (2017) que estes depósitos de sujidades são fatores de degradação do aspecto advindos de fontes como poluição atmosférica, umidade por infiltrações ou por exposição aos ciclos de chuva. As sujidades estão enquadradas segundo os autores referidos como manifestações patológicas que comprometem as superfícies das fachadas, com consequências significativas para a edificação. A umidade é um fator que influencia particularmente na aderência de sujidades nas fachadas e na proliferação de vegetação parasitária como os fungos. O desenvolvimento de colônias de fungos causa alterações estéticas nas fachadas gerando uma coloração que pode oscilar de manchas claras até tonalidades escuras como marrom e preto (SHIRAKAWA,1995). Caso em que se enquadra o Pavilhão Luiz Nunes.

\section{CONCLUSÃO}

Regiões como a do bairro do Derby, onde se localiza a edificação, são propícias para este tipo de manifestação por causa das características da vegetação. Ao passo que a edificação se encontra em uma área rica em vegetação, há grande probabilidade de existir focos de cupim no terreno, que se beneficiam da falta de manutenção das edificações. Ainda, um fato que influencia a ação destes insetos também pode ser oriundo das próprias características do projeto. Por este estar vinculado diretamente ao solo, a entrada de cupins na edificação é facilitada em razão da natureza destes seres que se beneficiam da umidade do subterrâneo para se desenvolver.

A presença destes microrganismos existentes na fachada do edifício no momento do desenvolvimento deste trabalho e já relatada em análises patológicas executadas anteriormente, como mostrado neste estudo; assim como o reaparecimento de cupins e as esquadrias constantemente degradadas são efeito da ausência de manutenção periódica na edificação. É importante o envolvimento dos arquitetos na questão da manutenção de prédios históricos e mesmo destes que não possuem caráter excepcional. É necessária uma maior compreensão da importância da necessidade de planos de manutenção para evitar desgastes, principalmente após processos de restauro no afim de evitar intervenções dispendiosas e invasivas no futuro. A falta de consideração pelo valor da arquitetura moderna, sendo um dos patrimônios brasileiros mais preteridos em razão da ausência de uma ancestralidade reconhecida, ocasiona situações como a do Pavilhão Luiz Nunes. A carência de investimentos faz com que esforços de profissionais como o arquiteto Luiz Amorim e demais membros do IAB, encontrem barreiras no que tange a salvaguarda física da edificação. 
Os processos de manutenção preventiva são primordiais para a conservação destes imóveis. Quando se aborda a necessidade de manutenção de qualquer tipo de imóvel, considera-se as perdas patrimoniais e humanas, entretanto quando se trata de um imóvel histórico, além das perdas relatadas, existe o agravante da perda de um patrimônio que faz parte da identidade e da história de uma localidade e povo. Com o novo processo de restauro que visa trazer vida e dignidade ao local, iniciado a partir de acordos entre a Universidade Federal de Pernambuco e o Instituto de Arquitetos do Brasil em Pernambuco, melhores dias para o Pavilhão são aspirados.

\section{REFERÊNCIAS}

ANDRADE, P. R.; CÂMARA, A. N. D.; MEDINA, L. L. Edifício do Pavilhão de Óbitos do Recife: uma experiência de restauro de Arquitetura Moderna. Quinta edição do Docomomo. Outubro de 2003. p. 12.

BARATTO, R. MoMA disponibiliza para download "Brazil Builds": o livro que apresentou a arquitetura brasileira para o mundo. Arch Daily 18 de janeiro de 2018. Disponível em:

<https://www.archdaily.com.br/br/887193/moma-disponibiliza-para-download-brazil-builds-o-livro-que-apresentou-aarquitetura-brasileira-para-o-mundo>. Acesso em: 07 jun. 2019.

BAUER, L. A. F. Materiais de construção. 3. ed. Rio de Janeiro: LTC - Livros Técnicos e Científicos, 1987.

CARVALHO, Y. N. P.; LEANDRO, F. S.; JÚNIOR, F. C. N. G.; LÊU, A. A. M.; SILVA, Ú. R. L. Manifestações Patológicas com Foco em Fachadas de Conjunto Habitacional de Baixa Renda na Cidade de Juazeiro do Norte/CE. CONPAR - Conferência Nacional de Patologias e Recuperação de Estruturas, 2017. Disponível em: <http://revistas.poli.br/index.php/CONPAR/article/view/627>. Acesso em: 22 nov. 2019.

Eco Focus. Danos causados pelos cupins na construção civil. 28 de janeiro de 2015. Disponível em: <http://ecofocuscontroledepragas.com.br/blog/cupins-na-construcao-civil/ >. Acesso em: 20 nov. 2019.

FUNDARPE, Antigo Pavilhão de Verificação de Óbitos da Faculdade de Medicina - Atual Sede de IAB/PE. Processo n. 2211-31/1984. p. 42.

GALLO, D. (in memorian) et. al. Entomologia agrícola. Piracicaba: FEALQ, 2002. Disponível em: <https://ocondedemontecristo.files.wordpress.com/2013/07/livro-entomologia-agrc3adcola-_jonathans.pdf >. Acesso em: 25 out. 2019.

GONZAGA, A. L. Madeira: uso e conservação. Brasília - DF: IPHAN/MONUMENTA,2006. 246 p.: il. ;28 cm (Cadernos Técnicos; 6). Disponível em: 〈http://portal.iphan.gov.br/publicacoes/lista?categoria=\&busca=\&pagina=27>. Acesso em: 28 nov. 2019.

HELENE, Paulo R.L. Manual para reparo, reforço e proteção de estruturas de concreto. Paulo Helene: [Consultor Maurício Gerschenstein; Coordenação Paulo Sérgio F. Oliveira, Fernando A.P. Guimarães, Sérgio Garra]. - 2 ed. São Paulo: PINI,1992.

MEDEIROS, P.; NASLAVSKY, G.; AMORIM, L. Full Documentation Fiche, 2003. p.09. Disponível em: <http://docomomo.org.br/old/homework/Full_Documentation_Fiche_Pavilhao_de_Verificacao_de_Obitos.pdf >. Acesso em: 09 jun. 2019.

NASLAVSKY, G. Arquitetura moderna no Recife: 1949-1972. Recife: E. da Rocha, 2012.

ROCHA, E. de A. Manifestações patológicas em edificações religiosas do Século XVI e XVII: Um estudo na região do Sítio Histórico de Olinda - PE. Recife: Dissertação de Mestrado - UPE, Escola Politécnica, 2017. 174 f.: il.

SHIRAKAWA, M. A.; MONTEIRO, M. B.; SELMO, S. M.de S.; CINCOTTO, Maria Alba. Identificação de fungos em revestimentos de argamassas com bolor evidente. Anais. Goiania: UFGO, 1995. Disponível em:

<https://www.gtargamassas.org.br/eventos/file/36-identificacao-de-fungos-em-revestimentos-de-argamassa-com-bolorevidente>. Acesso em: 31 out. 2019.

TINOCO, J. E. L. Mapa de danos: recomendações básicas. Textos para discussão. v. 43. Série 2 - Gestão de Restauro. Olinda: Centro de Estudos Avançados da Conservação Integrada, 2009. p. 21. 